\title{
Formal Foundations for Semantic Theories of Nominalisation
}

\author{
Fritz Hamm/Michiel van Lambalgen \\ friedrich.hamm@uni-tuebingen.de/vanlambalgen@hum.uva.nl
}

\begin{abstract}
This paper develops the formal foundations of semantic theories dealing with various kinds of nominalisations. It introduces a combination of an event-calculus with a type-free theory which allows a compositional description to be given of such phenomena like Vendler's distinction between perfect and imperfect nominals, iteration of gerunds and Cresswell's notorious non-arrival of the train examples. Moreover, the approach argued for in this paper allows a semantic explanation to be given for a wide range of grammatical observations such as the behaviour of certain types of nominals with respect to their verbal contexts or the distribution of negation in nominals.
\end{abstract}

Introduction

In chapter five of his book Linguistics in Philosophy, Zeno Vendler (Vendler 1967) discusses two classes of nominalised predicates, the class of perfect and the class of imperfect nominals, and further two types of verbal contexts which either do or do not admit these nominals as arguments. Vendler argues in support of the thesis that a genuine semantic difference is responsible for many of his observations. The nominals he investigates are assumed to denote, in different categories, the category of events for one class of nominals and the category of facts, results, or propositions for the other. In his work Vendler does not provide precise definitions of these concepts but introduces them by way of example. However, we entertain the thesis that his observations are central for any semantic theory dealing with natural language nominalisations. Therefore, in the sections to follow we will first briefly summarise Vendler's findings and related ones and then introduce the formal tools which we think are required for the foundations of a general semantics of nominalisations which claims explanatory value. Roughly, these tools consist of an event-calculus which allows a formal account to be given of the difference between events and facts etc. and a system which is capable of transforming sentences and predicates into terms, thus providing a theory of reification. It is the combination of the two systems that allows the development of explanatorily adequate logical representations for the data. Hence, in the last sections we will put the machinery thus developed to work and show how to derive semantically adequate explanations for a series of observations mainly from Vendler. The central purpose, however, is to show by analysing puzzling examples that the tools introduced are suited to forming the basis of a general theory of the semantic part of natural language nominalisations.

In the following two sections, we introduce the most important characteristics of Vendler's observations and philosophical claims.

\section{Two Types of Nominalisations}

\subsection{Perfect and Imperfect Nominals}

Vendler's differentiation between perfect and imperfect nominals and his observations about their most important properties are illustrated in the following two groups of examples. Perfect nominals occur with determiners, can be modified by adjectives but not by adverbs, 
and cannot appear in different tenses or be modalised. Further, it is impossible to negate perfect nominals. To summarise, perfect nominals are nominalised forms which have lost their verbal characteristics and behave like "real" nouns. This is why Vendler dubbed them perfect.
(a) the singing of the song
(b) beautiful singing of the song
(c) * quickly cooking of the dinner
(d) *having cooked of the dinner
(e) *being able to cook of the dinner
(f) * not revealing of the secret

Imperfect nominals show the opposite behaviour, as the examples in (2) demonstrate. They cannot occur with nominal determiners, they can be modified by adverbs ${ }^{1}$ but not by adjectives, they can occur in different tenses, they can be modalised, and it is possible to negate them.
(a) *the singing the song
(b) *beautiful singing the song
(c) singing the song beautifully
(d) quickly cooking the dinner
(e) having cooked the dinner
(f) being able to cook the dinner
(g) not revealing the secret

Hence, imperfect nominals can occur externally in noun phrase positions, but their internal structure strongly resembles the structure of the VP or the $\mathrm{S}$ they are derived from. This is, of course, the reason why Vendler called them imperfect. We shall henceforth use the term perfect or imperfect nominal both for the respective nominal and for the NP which contains such a nominal.

Abney (1987) develops a detailed syntactic account of gerunds, which are part of the class of perfect and imperfect nominals. He distinguishes four classes of gerunds:
(a) Acc-ing: John being a spy.
(b) PRO-ing: singing loudly.
(c) Poss-ing: John's knowing the answer.
(d) Ing-of: singing of the song.

Assuming that PRO-ing is a special case of Acc-ing or Poss-ing, there are three classes of gerunds, which differ with respect to their syntactic properties. For example, Abney shows that Acc-ing and Poss-ing constructions show differences with regard to agreement, long distance binding, pied piping, etc. But what about semantic differences? Of course, Ing-of gerunds and Poss-ing gerunds are among the perfect and imperfect ${ }^{2}$ nominals introduced in this section, and Vendler's thesis is that there is a category distinction, i.e. something

\footnotetext{
1 They can therefore occur with adverbial determiners like always.

${ }^{2}$ The concepts perfect and imperfect nominal are used by Vendler primarily to refer to sets of structural properties which are assumed to be conditioned by two different semantic types. This is especially clear when imperfect nominals are considered. This is a huge and structurally heterogeneous class including Poss-ing, Accing gerunds, absolutive constructions, infinitives and even that-clauses, which are traditionally not thought of as nominal at all. Perfect nominals, however, are more coherent. This class contains Ing-of gerunds and some derived nominals like blizzard etc.
} 
genuinely semantic, involved with these notions. In this paper it will be assumed that Acc-ing and Poss-ing constructions are semantically in the same class, the class of imperfect nominals.

Vendler (1968) demonstrates that the genitive in Poss-ing gerunds is not a "real" genitive like John's in John's house. This is shown by the following examples:

(4) (a) John's house

(b) the house of John

(c) John's singing the song

(d) * the singing the song of (by) John

(e) the singing of the song by John

Example (4b) is a paraphrase of (4a). An analogous paraphrase for (4c) does not exist.

Compared with the genitive of imperfect nominals the genitive of perfect nominals behaves like a "real" genitive. This is also shown by the following observation: It is possible to delete the genitive of embedded imperfect nominals if it is coreferential with the matrix subject. Deletion in the case of perfect nominals, however, leads to ungrammaticality.

(a) He shocked us by telling a dirty joke.

(b) $\quad *$ He entertained us by singing of arias. (Vendler 1968: 50)

We therefore will analyse the genitive in Poss-ing constructions in the same way as the subjects of Acc-ing gerunds. For more arguments in favour of the claim that the genitive of Poss-ing gerunds is not the same as the genitive in Ing-of nominals, see Vendler (1968).

\subsection{Narrow and Loose Containers}

Vendler also considers verbal contexts, which somehow discriminate between the above two classes of nominals. Expressions like surprised us, is unlikely are examples of loose containers. Their name derives from the fact that they accept both kinds of nominals as arguments, as shown in (6).

(6) (a) The beautiful singing of the aria surprised us.

(b) John's not revealing the secret is unlikely.

(c) The singing of the song is fun.

(d) John's quickly cooking the dinner surprised us.

(e) They were surprised by the sudden coming in of a stranger.

Verbal contexts like was slow, occurred, etc., which are called narrow by Vendler, show more restrictive behaviour. They accept as arguments only perfect nominals, as shown in (7).

(7) (a) *The soprano's singing the aria was slow.

(b) The soprano's singing of the aria was slow.

(c) John's revealing of the secret occurred at midnight.

(d) *John's revealing the secret occurred at midnight.

(e) *John's not revealing the secret occurred at midnight.

Narrow containers can be negated, and they stay narrow under negation, as the following examples demonstrate.

(8) (a) The singing of the song didn't occur at noon.

\footnotetext{
${ }^{3}$ This example is from Jespersen (1933: 327).
} 
(b) *John's kicking the cat didn't occur at noon.

As already mentioned, negations of perfect nominals are usually bad, but they may occur marginally as in the following example from R. Cooper:

?Andrew's not stopping for the traffic light took place at noon.

But note that even if example (9) is acceptable, the negation will not be interpreted in a classical way but as an antonym, i.e. similar to E. Engdahl's example concerning naked infinitive complements of perception verbs.

The policeman saw Andrew not stop for the traffic light.

Antonymic negation is characterised by the following pair of conditions, where $\neg$ signifies classical negation and $\sim$ antonymic negation:

$$
\sim \varphi \rightarrow \neg \varphi \text { but not } \neg \varphi \rightarrow \sim \varphi
$$

From the fact that $x$ is black we certainly are allowed to conclude that $x$ is not white, but by no means can we conclude from the fact that $x$ is not white that $x$ is black.

Note that the nominals arrival of the train and non-arrival of the train in the following examples, though similar to perfect and imperfect nominals in many respects, nevertheless behave differently. It may well be that arrival of the train is a perfect nominal, but nonarrival of the train is not an imperfect nominal in Vendler's sense because it can occur with nominal determiners and adjectives but not with adverbs.

(11) (a) The arrival of the train surprised us.

(b) The non-arrival of the train surprised us.

(c) The arrival of the train occurred at noon.

(d) *The non-arrival of the train occurred at noon.

(e) the unexpected non-arrival of the train

(g) *the non-arrival of the train unexpectedly

In Russian ${ }^{4}$, nominalisations like penie (singing), otkrytie (discovery) prichod (arrival) and sobljudenie (respecting) show similar behaviour to English perfect nominals. For example, these nominals do not express temporal or modal differentiations. However, they can be negated with the prefix ne, which for instance results in the noun nesobljudenie. The meaning of nesobljudenie is a very strong form of negation which is similar to the marginal English not stopping for the traffic light; i.e. ne is interpreted as an antonymic negation. However, Ilse Zimmermann informed us that nesobljudenie can also be similar to the non in the English phrase non-arrival of the train, which - as will be shown in section 5.4 - results in a much more complicated interaction of different kinds of negation. But this second reading seems to be less prominent.

Antonym-like negations occur not only in nominalisations. For example, as already mentioned, certain perception verb complements show similar behaviour under negation. Moreover, this kind of negation is observed in the context of so-called Neg-Raising constructions.

\footnotetext{
${ }^{4}$ We thank Katja Jasinskaja and Ilse Zimmermann for informing us about the negation of Russian nominalisations. For more information about negation and nominalisation in Russian, the reader is referred to Zimmermann (1988).
} 
(12) (a) Daniel does not claim that Louise came.

(b) Daniel claims that Louise didn't come.

The negation occurring in (12b) is not interpreted in a classical way but as antonym; (12a) may be ambiguous between the two readings. For an analysis of Neg-Raising structures using negation as failure, see Tovena (2001).

Narrow containers are typical examples of extensional contexts in contrast to loose containers ${ }^{5}$ :

(13) (a) The beheading of the tallest spy occurred at noon.

(b) The beheading of the tallest spy surprised us.

If the king and the tallest spy happen to be the same person, then it follows from (13a) that The beheading of the king occurred at noon. But certainly The beheading of the king surprised us does not follow from (13b).

Vendler's description of the meanings of perfect and imperfect nominals and their respective containers is rather vague, but he clearly suggests that a category distinction between events and facts or results forms the philosophical basis for these empirical findings. Events are taken to somehow be related to the meaning of perfect nominals, and facts or results to the meaning of imperfect nominals. We think it is fair to interpret Vendler as claiming that the relationship between the nominals and their respective containers is determined by this category distinction, but it is certainly unclear (a matter of debate?) whether he wants the other findings to be interpreted in this way or as conditioned by structural (i.e. syntactic) properties of English.

Schachter suggests that some gerunds - his gerundive nominals - behave like names.

"To return to gerundive nominals, I would claim that gerundive nominals without initial possessives or other determiners are also class names naming a type of activity in which one can participate, a type of condition, etc." (Schachter 1976: 215)

If we assume that imperfect nominals are like names, then this assumption accounts immediately for the lack of determiners in such phrases since names can in general not occur with determiners ${ }^{6}$. This assumption is further supported by the following observation from Pullum (1991):

\section{(14) *his leaving her that you predicted}

Neither Acc-ing nor Poss-ing gerunds tolerate restrictive relative clauses. One further observation supporting Schachter's proposal is that Ing-of nominals can sometimes be pluralised but Acc-ing and Poss-ing gerunds definitely can't. The following example is from Poutsma (1923).

(15) He ignored the sayings and doings of the ladies of his family.

Observations from Abney (1987: 244), moreover, show that perfect and imperfect nominals also differ in their ability to participate in N-bar deletion. For instance, an ellipsis with a Possing construction as in (16a) is bad, while it is possible with an Ing-of gerund and a narrow container as shown in (16b).

\footnotetext{
'The examples are from Parsons (1990).

${ }^{\circ}$ In many languages - for example German - the definite article can occur with proper names; i.e. der Peter is grammatical. But note that this is restricted to the definite article (ein Peter is out). In some languages the definite article even functions as a kind of nominaliser. An example is ancient Greek (see Koptjevskaja-Tamm 1993). For a more careful discussion of this topic see Hamm (1999). An instructive discussion of the historical development of the English gerundial system is Hindsill (2001).
} 
(16) (a) *John's fixing the sink was surprising, and Bill's was more so.

(b) John's fixing of the sink was skillful, and Bill's was more so.

Abney claims that the gerund John's fixing of the sink is ambiguous and can either refer to the manner in which John fixed the sink - called the Act-reading by Abney - or the fact that John fixed the sink (Fact-reading). N-bar deletion is only possible under the Act-reading.

Of course Abney does not develop a formal semantics for his Fact- and Act-readings. In his work these concepts are just labels which are used to name the intuitive reason for observations like the one above. In the following pages we will develop a formal theory which allows us to give a precise reconstruction of Abney's notions. His Act-reading will be described in terms of event-types and his Fact-reading in terms of fluents. These formal concepts are introduced in section 4 .

Finally, we note the following examples of iterated nominalisations, a phenomenon which was not observed by Vendler.

(17) (a) John's supporting his son's not going to church

(b) John's improving his singing

(c) John's watching the dog's playing

(d) my discovering her not leaving

(e) his discussion of John's revealing the secret

We are interested in these examples because the negation in say (17a) seems to have antonymic force, and all examples seem to be factive in the sense that they presuppose that the fact expressed by the embedded nominal holds. For instance (17a) implies that John's son is not going to church.

In this paper only the Act- and Fact-readings of gerunds are considered. The habitual or generic reading of a gerund like eating apples will be neglected ${ }^{7}$.

\section{Syntax}

In this section we will briefly mention Abney's syntactic analysis of English gerunds. Our main purpose here is to show that the formal apparatus we will develop in the following sections allows a strictly compositional interpretation of the discussed nominalisations. However, although we will be concerned with Abney's work, we want to stress that the proposed interpretation process is not tied to a specific syntactic framework. For example, in Hamm/van Lambalgen (2000) we show how to interpret Pullum's GPSG-based theory of nominal gerund phrases (Pullum 1991) which are Abney's Poss-ing gerunds in a strictly compositionaal way too.

Abney's account is based on a conservative extension of classical $\mathrm{X}^{\prime}$-theory. It is conservative in the sense that it does not eliminate any inferences of $\mathrm{X}^{\prime}$-theory on the phrasal level. Abney's approach differs from the classical theory only in so far as he assumes that the function of the affix -ing is to convert a verbal category into a nominal one. The essence of his analysis is then that the differences in the structures of the various types of English gerunds reduce to the question of where in the projection path of the verb this conversion takes place. It is presumed that -ing can only be adjoined to the lexical category $\mathrm{V}$ and to the maximal projections VP and IP. Furthermore, it is assumed that this abstract morphological element does not have a syntax of its own in the sense that it does not project any structure. This assumption allows $\mathrm{X}^{\prime}$-theory to be kept intact at the phrasal level.

\footnotetext{
${ }^{7}$ See Portner (1991) for a discussion of such examples.
} 
If -ing is sister of IP, the resulting s-structure is that of Acc-ing. Abney assumes that at LF the verb sing is raised to ing.

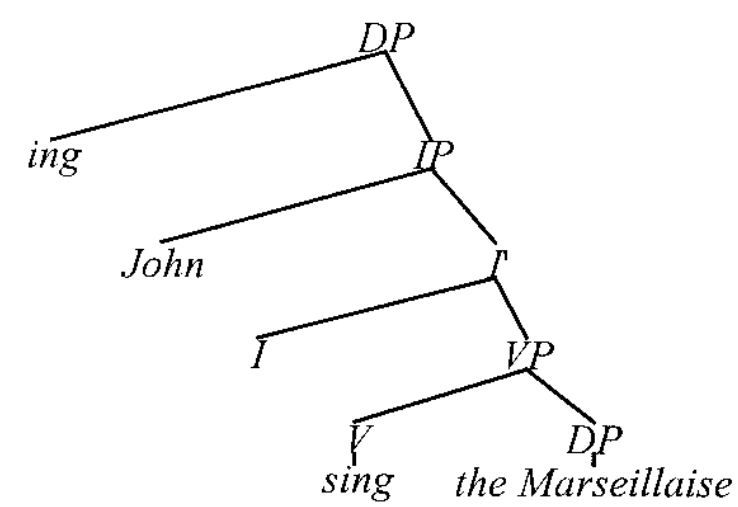

Acc-ing

In Poss-ing gerunds, -ing is sister of VP, and in Ing-of structures ing occupies the lowest place in the tree. Therefore, we arrive at the following two structures.

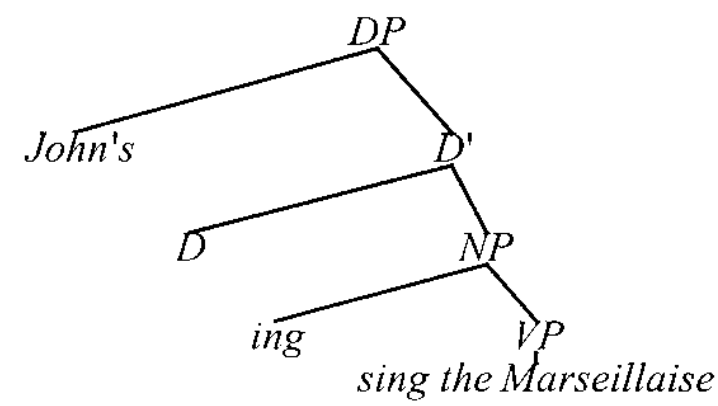

Poss-ing

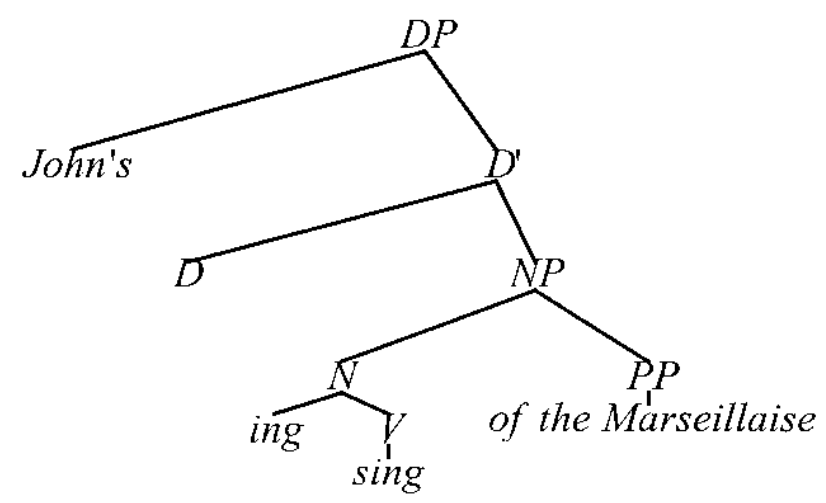

Ing-of

We will slightly deviate from Abney's analysis here in assuming two different -ings - one, -ing, for Acc-ing and Poss-ing and the other, -ing of, for Ing-of structures. The reason for this is that the semantic effect of -ing in Ing-of gerunds is slightly different from the effect -ing has for the other types of gerunds. Following Chomsky (1981) in assuming a rule of of-insertion, the following syntactic structure for Ing-of gerunds will be the input for semantic interpretation. 


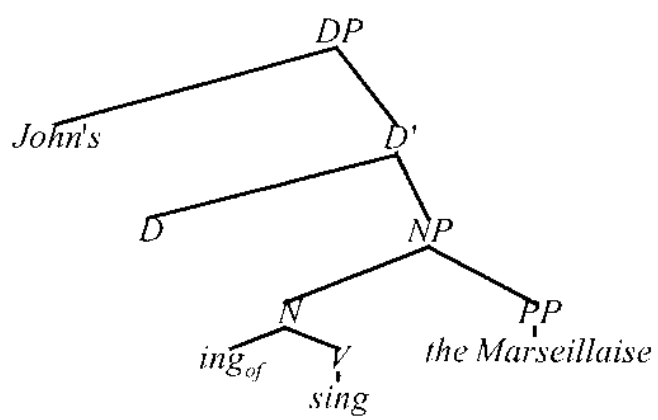

Ing-of

\section{$4 \quad$ Formal Framework}

The literature contains several formalisms for the semantics of events. A prominent example is Parsons (1990). But in this tradition, predicates like Hold or $\mathrm{Cul}$ which are intended to intuitively capture distinctions between different kinds of eventualities are not axiomatised and therefore formally empty. The literature in artificial intelligence also contains formalisms for reasoning about events, which have their roots in planning and are axiomatised. It has been suggested several times ${ }^{8}$ that such formalisms might be useful for the semantics of natural language, although Hamm/van Lambalgen (2000) seems to be the first paper where the actual computations are done.

We will work with a variation of an event-calculus developed in Shanahan (1997) and combine this formalism with a type-free logical system" proposed by Feferman (1984). By combining the two systems, we derive a theory of reification for different kinds of eventualities. This will be explained in the next two sections.

\subsection{Event Calculus}

The event-calculus is a many-sorted first order logic with sorts for individuals real numbers, representing time, fluents and event-types marking the beginning and end of fluents. Fluents can be thought of as time-dependent properties; i.e. we expect that they hold or don't hold at a certain time t. Event-types are objects which initiate or terminate the life of a fluent. In contrast to fluents, these objects don't hold but rather happen.

Given this ontology, the following choice of basic predicates seems natural. We want to be able to say that fluents are initiated and terminated by events, or that a fluent held or was true at the beginning of time. If $\mathrm{f}$ is a variable over fluents, e a variable over events, and $\mathrm{t}$ a variable over time points, we may write the required predicates as

$$
\begin{array}{ll}
\text { - } & \text { Initially }(\mathrm{f}) \\
\text { - } & \text { Inappens }(\mathrm{e}, \mathrm{t}) \\
\text { Initiates }(\mathrm{e}, \mathrm{f}, \mathrm{t}) \\
& \text { Terminates }(\mathrm{e}, \mathrm{f}, \mathrm{t})
\end{array}
$$

Intuitively Initially $(\mathrm{f})$ means that at the beginning of time fluent $\mathrm{f}$ holds. Happens(e, $\mathrm{t})$ says that event-type e takes place at time t. Therefore, the pair $(e, t)$ may be thought of as a specific

\footnotetext{
${ }^{8}$ For instance in Steedman (1997).

${ }^{9}$ Standard logical system distinguish strictly between the set of terms and the set of formulas. Only terms are allowed as arguments in formulas. For example if $\mathrm{P}(\mathrm{x})$ and $\mathrm{Q}(\mathrm{y})$ are formulae formed from one place predicates $P, Q$ and variables $x, y$ an expression like $P(Q(y))$ is not well-formed. Type-free systems contain means to interpret expressions like the above. In the system presented in section 2.2 this is achieved via an abstract form of Gödelisation.
} 
event-token and the set Happens as the set of event-tokens. Initiates(e, f, t) encodes one possible action of an event-type. It is true at time $t$ if event-type e causes the time dependent property $\mathrm{f}$ to hold. It is assumed that $\mathrm{f}$ does not hold at $\mathrm{t}$. Terminates $(\mathrm{e}, \mathrm{f}, \mathrm{t})$ is the converse of Initiates. It encodes the other possible action of an event-type. This predicate says that at time $t$ event-type e brings it about that fluent $f$ ceases to hold. It is assumed that $f$ holds at $t$.

The predicate $\operatorname{Holds} A t(\mathrm{f}, \mathrm{t})$ says intuitively that time dependent property f holds at time $\mathrm{t}$ or is true at time t. The combination with Feferman's type-free system will turn HoldsAt into a truth predicate.

Shanahan's calculus also contains the predicates Trajectory and Releases, which will not be used for the analysis of nominalisations. We therefore present here a simplified axiomatisation of his calculus. The two additonal predicates allow continous change and changing partial objects to be modelled. In Hamm/van Lambalgen (2000) they are used to provide an axiomatised account for the semantics of the progessive.

We introduce two special predicates for f-relevant events. Clipped $\left(\mathrm{t}_{1}, \mathrm{f}, \mathrm{t}_{2}\right)$ expresses that there is a terminating event between $\mathrm{t}_{1}$ and $\mathrm{t}_{2}$; the second predicate Declipped $\left(\mathrm{t}_{1}, \mathrm{f}, \mathrm{t}_{2}\right)$ expresses that there is an initiating event between $t_{1}$ and $t_{2}$. Therefore Clipped $\left(\mathrm{t}_{1}, \mathrm{f}, \mathrm{t}_{2}\right)$ says that between $t_{1}$ and $t_{2}$ some event happened which caused $f$ not to hold. Declipped $\left(t_{1}, f, t_{2}\right)$ is the opposite of Clipped $\left(t_{1}, f, t_{2}\right)$. It says that between $t_{1}$ and $t_{2}$ an initiating event for fluent $f$ occurred.

The axioms of the event calculus given below are a modified and simplified version of Shanahan (1997). In the following, all variables are assumed to be universally quantified. The set of axioms of the event calculus will be abbreviated by $E C$.

Axiom $1 \quad$ Initially $(\mathrm{f}) \wedge \neg \operatorname{Clipped}(0, \mathrm{f}, \mathrm{t}) \rightarrow \operatorname{HoldsAt}(\mathrm{f}, \mathrm{t})$

Axiom 2 Happens $(\mathrm{e}, \mathrm{t}) \wedge \operatorname{Initiates}(\mathrm{e}, \mathrm{f}, \mathrm{t}) \wedge \mathrm{t}<\mathrm{t}^{\prime} \wedge \neg \operatorname{Clipped}\left(\mathrm{t}, \mathrm{f}, \mathrm{t}^{\prime}\right) \rightarrow$ $\operatorname{Holds} A t\left(\mathrm{f}, \mathrm{t}^{\prime}\right)$.

Axiom $3 \quad$ Happens $(\mathrm{e}, \mathrm{t}) \wedge$ Terminates $(\mathrm{e}, \mathrm{f}, \mathrm{t}) \wedge \mathrm{t}<\mathrm{t}^{\prime} \wedge \neg \operatorname{Declipped}\left(\mathrm{t}, \mathrm{f}, \mathrm{t}^{\prime}\right) \rightarrow$ $\neg$ HoldsAt $\left(\mathrm{f}, \mathrm{t}^{\prime}\right)$.

Axiom 4 Happens $(\mathrm{e}, \mathrm{s}) \wedge \mathrm{t}<\mathrm{s}<\mathrm{t}^{\prime} \wedge$ Terminates $(\mathrm{e}, \mathrm{f}, \mathrm{s}) \rightarrow \operatorname{Clipped}\left(\mathrm{t}, \mathrm{f}, \mathrm{t}^{\prime}\right)$.

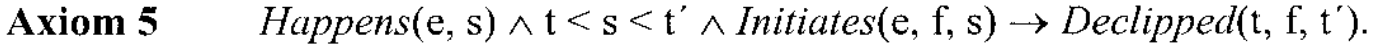

Let us first explain Axiom 2 (Axiom 1 is similar). This axiom says that if at time $t$ an event $e$ happened which initiated a fluent $\mathrm{f}$ and, moreover, if between $\mathrm{t}$ and $\mathrm{t}^{\prime}$ nothing interfered which terminated the life of $\mathrm{f}$, then we know that at time $\mathrm{t}^{\prime}$ fluent $\mathrm{f}$ still holds. Axiom 3 treats the parallel case for a fluent not holding at a time $t^{\prime}$. Axiom 4 and 5 constrain the meanings of the fluent relevant predicates Clipped $\left(t, f, t^{\prime}\right)$ and Declipped $\left(t, f, t^{\prime}\right)$. For instance, Axiom 4 informs us that if an event happens between $t$ and $t$ ' which terminates the life of fluent $f$, then this fluent is clipped between $t$ and $t^{\prime}$.

In the usual set-up of the event calculus, it is only said that HoldsAt is a truth predicate; the defining axioms for the truth predicate are lacking since the language of the event-calculus does not allow the characteristic truth axiom to be stated. To see this more clearly, consider a formula $\varphi(a)$ with a temporal parameter a. We would like to map this formula to a fluent $f$ and then formulate the following truth axiom:

$\operatorname{Holds} A t(\mathrm{f}, \mathrm{t}) \leftrightarrow \varphi(\mathrm{t})$ 
However the language of the event-calculus does not have the means to do this. What we need is a method to transform formulas into terms. This is termed reification in Artificial Intelligence. Before developing the necessary machinery, let us first give some linguistic reasons - due to Chierchia (1989) - why such an operation of reification seems to be required. Consider:
(a) Being home is nice.
(b) To be home is nice.
(c) John is nice.

Semantically John, the gerund being home and the infinitive to be home are arguments of the propositonal function is nice. But this is not possible with finite verb phrases as in (20).
(a) *Are home is nice.
(b) * Is home is nice.

Chierchia therefore adheres to the old Fregean idea of conceiving of a function both as something which requires an argument, and as an object. In the examples above, the object correlate of the (propositional) function are home is the gerund being home or the infinitive to be home. Since these are both of the same semantic type as the proper name John, the examples in (18) are predicted to be acceptable. By contrast the expressions are home and is home in (19) are of a higher (function) type and for this reason are not acceptable as arguments of the propositional function is nice. This argumentation explains the observations in (18) and (19). The gerund and the infinitive here are the reified versions of their finite pendants.

\subsection{Feferman Theories}

Let $\mathrm{L}_{0}$ be a first order language and $\mathrm{S}_{0}$ be a theory formulated in $\mathrm{L}_{0}$. We assume that $\mathrm{S}_{0}$ admits a pairing scheme. This means that we reqire $L_{0}$ to contain a constant 0 , two unary function symbols $\pi_{1}$ and $\pi_{2}$ and a binary function symbol $\pi$ for which we will write (,). Furthermore we assume that $\mathrm{S}_{0}$ proves

$$
\begin{aligned}
& \pi(x, y)=(x, y) \neq 0 \\
& \pi_{1}(x, y)=x \\
& \pi_{2}(x, y)=y
\end{aligned}
$$

Given a model $M_{0}$ of $S_{0}, \pi$ will be interpreted as a pairing function, i.e. as a function which maps an element of the cartesian product $M \times M$ to an element of $M$ in such a way that the components can be recovered via the functions $\pi_{1}$ and $\pi_{2}$. We can now use induction to define the coding of $n$-tupels for arbitrary $n$. These requirements suffice to define an abstract form of Gödel numbering. We will henceforth write $\langle\varphi\rangle$ for the Gödel number of $\varphi$ in $L_{0}$ and possible extensions thereof.

Now let $\varphi$ be a formula with free variables among $o_{1}, \ldots, o_{k}, y_{1}, \ldots, y_{m}$. The term $\left(\langle\varphi\rangle, \mathrm{y}_{1}, \ldots, \mathrm{y}_{\mathrm{m}}\right)$ in $\mathrm{L}_{0}$ contains contains $\mathrm{o}_{1}, \ldots, \mathrm{o}_{\mathrm{k}}$ as bound variables and $\mathrm{y}_{1}, \ldots, \mathrm{y}_{\mathrm{m}}$ as free variables or parameters. The following definition makes sense:

Definition $1 \quad \varphi\left[\hat{o}_{1}, \ldots, \hat{o}_{k}, \mathrm{y}_{1}, \ldots, \mathrm{y}_{\mathrm{m}}\right]=\left(\langle\varphi\rangle, \mathrm{y}_{1}, \ldots, \mathrm{y}_{\mathrm{m}}\right)$. The variables $\mathrm{o}_{1}, \ldots, \mathrm{o}_{\mathrm{k}}$ are bound by abstraction in this term. We will also use standard set theoretical notation for $\mathrm{k}=1$ and write for $\left\{\mathrm{o} \mid \varphi\left(\mathrm{o}, \mathrm{y}_{1}, \ldots, \mathrm{y}_{\mathrm{m}}\right)\right\}=\varphi\left[\hat{o}, \mathrm{y}_{1}, \ldots, \mathrm{y}_{\mathrm{m}}\right]$. 
Let us see how to use this notation to formalise Chierchia's examples. To this end, let home $(0, \mathrm{a})$, and nice $(\mathrm{o}, \mathrm{a})$ be predicates with a temporal parameter a. The sentence John is home at time $a$ with $\mathrm{j}$ as a constant for John will therefore be formalised as: home $(\mathrm{j}, \mathrm{a})$. For the formal representation of the gerund being home let us choose the term home[ô,â]. Then the formula nice(home[ô,â],t) is a well formed expression representing the sentence Being home is nice at time $t$. Since are home would be rendered as home $(0, a)$ we get the unacceptable representation nice(home $(0, a), t)$ for $(19)(a)$. The representation is unacceptable because home $(\mathrm{o}, \mathrm{a})$ is not a term and can therefore not occur as argument of the predicate nice. This accounts for the difference between (18) and (19).

We now add "truth predicates" $T_{n}$ to $\mathrm{L}_{0}$ and extend the original system $\mathrm{S}_{0}$ by truth axioms, thereby forming an enriched system $\mathrm{S}$. The intuitive meaning of $T_{n}\left(\mathrm{x}_{1}, \ldots, \mathrm{x}_{\mathrm{n}}, \mathrm{z}\right)$ is that the tuple $\left(\mathrm{x}_{1}, \ldots, \mathrm{x}_{\mathrm{n}}\right)$ satisfies the formula coded by $\mathrm{z}$. The following axiom scheme therefore makes sense.

Axiom 6

$$
T_{n}\left(\mathrm{x}_{1}, \ldots, \mathrm{x}_{\mathrm{n}}, \varphi\left[\hat{\mathrm{o}}_{1}, \ldots, \hat{\mathrm{o}}_{\mathrm{n}}, \mathrm{y}_{1}, \ldots, \mathrm{y}_{\mathrm{m}}\right]\right) \leftrightarrow \varphi\left(\mathrm{x}_{1}, \ldots, \mathrm{x}_{\mathrm{n}}, \mathrm{y}_{1}, \ldots, \mathrm{y}_{\mathrm{m}}\right)
$$

Special cases of the above axiom scheme are:

$$
T_{0}\left(\varphi\left[\mathrm{y}_{1}, \ldots, \mathrm{y}_{\mathrm{m}}\right]\right) \leftrightarrow \varphi\left(\mathrm{y}_{1}, \ldots, \mathrm{y}_{\mathrm{m}}\right)
$$

For $m=0$ and $\varphi[]=\langle\varphi\rangle$, this results in the famous Tarskian scheme:

$$
T_{0}(\langle\varphi\rangle) \leftrightarrow \varphi
$$

For $T_{l}$, we get the set theoretic principle known as comprehension, which is of special importance in this paper since it will turn out that $T_{l}=$ Holds At.

$$
T_{l}\left(\mathrm{x},\left\{\mathrm{o} \mid \varphi\left(\mathrm{o}, \mathrm{y}_{1}, \ldots, \mathrm{y}_{\mathrm{m}}\right)\right\}\right) \leftrightarrow \varphi\left(\mathrm{x}, \mathrm{y}_{1}, \ldots, \mathrm{y}_{\mathrm{m}}\right)
$$

This shows that for $T_{/}$we may as well write $\in$. Before we proceed, let us give a concrete example to demonstrate how $T_{l}$ works. Assume again that $\varphi(a)$ is a formula with a temporal parameter a, say burn $(\mathrm{j}$, the house, a) which is the formal representation of the proposition John burns the house at time a. Let us formalise the imperfect nominal derived from this proposition - John's burning the house - via the term burn[j, the house, â]. This term is allowed as an argument of $T_{l}$ or of HoldsAt. From the axioms of Feferman's calculus we thus derive:

$$
\text { Holds At (burn[j, the house, } \hat{\mathrm{a}}], \mathrm{t}) \leftrightarrow \text { burn }(\mathrm{j}, \text { the house, } \mathrm{t})
$$

Intuitively John's burning the house holds at a certain time $t$ if and only if the proposition John burns the house at time $t$ is true. This explains the observation that although imperfect nominals are not propositions they are nevertheless somewhat proposition-like. Terms that are allowed as arguments of HoldsAt are proposition-like in other respects too. For example, for those fluents which can be defined in $\mathrm{L}_{0}$, we can freely form conjunctions, disjunctions and negations according to the following recipe:

$$
\begin{aligned}
& \operatorname{HoldsAt}\left(\mathrm{f}_{1} \wedge \mathrm{f}_{2}, \mathrm{t}\right) \leftrightarrow \operatorname{Holds} A t\left(\mathrm{f}_{1}, \mathrm{t}\right) \wedge \operatorname{HoldsAt}\left(\mathrm{f}_{2}, \mathrm{t}\right)(\operatorname{similarily} \text { for } \vee) \\
& \neg \operatorname{HoldsAt}(\mathrm{f}, \mathrm{t}) \leftrightarrow \operatorname{HoldsAt}(\neg \mathrm{f}, \mathrm{t})
\end{aligned}
$$


However, for (23) it is crucial that the fluents are definable in $\mathrm{L}_{0}$. Without this restriction, iteration of the HoldAt-predicate would lead to a version of Russell's paradox. In order to avoid such paradoxes, Feferman splits the $T$-predicates into a positive and a negative part, thereby interpreting the $T$-predicates by pairs $\left(T, T^{\prime}\right)$ where $T$ contains the extension and $T^{\prime}$ the anti-extension of the respective predicate. The two are required not to overlap but are allowed to have gaps; i.e. there may be (codes of) formulas which are neither in $T$ nor in $T^{\prime}$. This causes $T^{\prime}$ to behave like an antonym; i.e. we have

$$
\begin{array}{ll}
T \wedge T^{\prime}=0 & \text { and } \\
T^{\prime} \rightarrow \neg T & \text { but not vice versa!! }
\end{array}
$$

This property of the calculus is important for the analysis of iterated nominalisations. To see this more clearly, consider again the iterated imperfect nominalisation John's supporting his son's not going to church. This expression presupposes that John's son is indeed not going to church. Moreover, it is clear that the negation in the embedded nominal has the force of an antonym. It is not classical negation but means that John's son refrains from going to church. Let us write $\mathrm{j}$ for John, s for John's son and c for church, so that the embedded imperfect nominal receives the following logical representation:

$$
\neg \text { going[s, c, â] }
$$

Now suppose that in order to account for the observed factivity the verb support is translated as:

$$
\operatorname{SUPPORT}(\mathrm{x}, \mathrm{f}, \mathrm{t}) \leftrightarrow \operatorname{HoldsAt}(\mathrm{f}, \mathrm{t}) \wedge \operatorname{support}(\mathrm{x}, \mathrm{f}, \mathrm{t})
$$

Under these assumptions the sentence John supports his son's not going to church will be represented as follows:

$$
\text { SUPPORT(j, ᄀgoing }[\mathrm{s}, \mathrm{c}, \hat{\mathrm{a}}], \mathrm{o})
$$

Transforming this proposition into a term again we finally arrive at the above iterated nominalisation.

$$
\text { SUPPORT } \mathrm{j}, \neg \text { going }[\mathrm{s}, \mathrm{c}, \hat{\mathrm{a}}], \hat{\mathrm{o}}]
$$

This term can occur as an argument of a loose container as in John's supporting his son's not going to church was considered by many a severe mistake. But now observe the following equivalences:

$$
\begin{aligned}
& \operatorname{HoldsAt}(\operatorname{SUPPORT} \mathrm{j}, \neg \operatorname{going}[\mathrm{s}, \mathrm{c}, \hat{\mathrm{a}}], \hat{\mathrm{o}}], \mathrm{t}) \leftrightarrow \operatorname{SUPPORT}(\mathrm{j}, \neg \operatorname{going}[\mathrm{s}, \mathrm{c}, \hat{\mathrm{a}}], \mathrm{t}) \leftrightarrow \\
& \operatorname{HoldsAt}(\neg \operatorname{going}[\mathrm{s}, \mathrm{c}, \hat{\mathrm{a}}], \mathrm{t}) \wedge \operatorname{support}(\mathrm{j}, \neg \operatorname{going}[\mathrm{s}, \mathrm{c}, \hat{\mathrm{a}}], \mathrm{t}) \leftrightarrow \\
& \neg \operatorname{HoldsAt}(\operatorname{going}[\mathrm{s}, \mathrm{c}, \hat{\mathrm{a}}], \mathrm{t}) \wedge \operatorname{support}(\mathrm{j}, \neg \operatorname{going}[\mathrm{s}, \mathrm{c}, \hat{\mathrm{a}}], \mathrm{t})
\end{aligned}
$$

These equivalences show that a negative occurrence is in the scope of HoldsAt, which means that $\neg \operatorname{HoldsAt}\left(\right.$ going [s, c, â], t) has to be interpreted by HoldsAt ${ }^{\prime}(\operatorname{going}[\mathrm{s}, \mathrm{c}, \hat{\mathrm{a}}], \mathrm{t})$ which is $T_{l}^{\prime}($ going $[\mathrm{s}, \mathrm{c}, \hat{\mathrm{a}}], \mathrm{t})$. This accounts for the antonymic force of the embedded negated imperfect nominal his son's not going to church in a completely systematic way.

An important feature of Feferman's calculus is that it limits the demonstrated partiality to the system $\mathrm{S}$ proper. To be more precise, Feferman proves a theorem which says that if $\mathrm{S}_{0}$ is a consistent system then there exists an extension $\mathrm{S}$ which contains truth axioms and which is conservative over $S_{0}$. 
"Conservative" here means that the expanded system $S$ does not touch the entailment relation of the system $S_{0}$. For instance, if we choose classical predicate logic as $S_{0}$, negation behaves classically for expressions from the system $S_{0}$. Nevertheless, it is important to keep in mind that negations with iterations of the HoldsAt-predicate always have antonymic force.

Although Feferman's calculus allows to introduce set-like objects $\phi[\hat{o}]$, which are usually written $\{\mathrm{o} \mid \phi(\mathrm{o})\}$, it is important to note that the axiom of extensionality in general fails; i.e. we do not have:

$$
\forall \mathrm{y}(\mathrm{y} \in\{\mathrm{o} \mid \phi(\mathrm{o})\} \leftrightarrow \mathrm{y} \in\{\mathrm{o} \mid \psi(\mathrm{o})\}) \rightarrow\{\mathrm{o} \mid \phi(\mathrm{o})\}=\{\mathrm{o} \mid \psi(\mathrm{o})\} \quad(=\phi[\hat{\mathrm{o}}]=\psi[\hat{\mathrm{o}}])
$$

Feferman's calculus, therefore, is a genuinely intensional calculus in which the identity of the objects $\phi[\hat{o}]$ and $\psi[\hat{o}]$ is not determined by their extensions.

To summarise, we have found a method to turn a formula $\varphi$ into a term $\langle\varphi\rangle$, which is allowed as an argument of the HoldsAt-predicate. Therefore, the combination of the eventcalculus with Feferman's type-free system permits the development of the required theory of reification. We have already shown how the combined theory allows denotations for imperfect nominals to be defined. But what about perfect nominals? The task here is to describe terms which are event-like and clearly distinguished from the proposition-like fluents. Since event-types don't contain temporal parameters, we choose to represent perfect nominals as $\exists$ a. $\varphi[\mathbf{x}, a]$, where $\mathbf{x}$ is a tuple of variables and a is a time parameter. To illustrate this definition, consider again the formula $\operatorname{burn}(\mathrm{x}$, the house, a). The formal representation of the perfect nominal burning of the house is the term $\exists \mathrm{a} . b u r n[\mathrm{x}$, the house, a]. This term is allowed to occur as argument of the Happens-predicate, but it is not of the right sort for the HoldsAt-predicate since the temporal parameter is bound by the existential quantifier. This also explains why event-types are not proposition-like entities, because the Happens-predicate is not a truth predicate and there is, therefore, no direct relationship between event-types and the corresponding propositions.

Hence we have arrived at the following two definitions:

Definition 1 If $\varphi(\mathbf{x}, a)$ is a formula, the event-type generated by $\varphi$ is the term $\exists$ a. $\varphi[\mathbf{x}, a]$.

Definition 2 The denotation of an imperfect nominal deriving from a formula $\varphi(\mathbf{x}, \mathrm{a})$ is the term $\varphi[\mathbf{x}, \hat{a}]$.

Event-tokens may be obtained from event-types by means of the Happens-predicate.

$$
\text { Happens }(\exists a . \varphi[\mathbf{x}, \mathrm{a}], \mathrm{t})
$$

An event-token thus is a pair consisting of an event-type and a time related by the Happenspredicate.

Let us briefly repeat the general idea of reification. Extensionally we can conceive of the denotation of a predicate as a function from a tuple of arguments to a truth value. For instance, $g o(x, y, a)$ assigns 1 or 0 to individuals $x, y$ and a time a. Reification changes the values of such a function. Instead of truth values, the reified formulas $\exists \mathrm{a} . g o[\mathrm{x}, \mathrm{y}, \mathrm{a}]$ and $g o[\mathrm{x}$, $y$, â] will denote two kinds of eventualities, the first event-types and the second fluents. These eventualities are distinguished by two predicates of the axiomatised event calculus: the HoldsAt-predicate, which says that a fluent holds at a certain time $\mathrm{t}$, and the Happenspredicate, which tells us that an event-type happens at a time t. The first predicate is a generalised truth predicate; i.e. it satisfies the equivalence $\operatorname{Holds} \operatorname{At}(g o[\mathrm{x}, \mathrm{y}, \mathrm{a}], \mathrm{t}) \leftrightarrow \operatorname{go}(\mathrm{x}, \mathrm{y}, \mathrm{t})$ for fluent term $g o[\mathrm{x}, \mathrm{y}, \hat{\mathrm{a}}]$. Hence, it mirrors the relationship between fluents and propositions. 
The second predicate is not a truth-predicate. It allows only event-types and times as arguments. The combined formal methods allow us to generate objects which are distinguished via the axioms of the event-calculus. These objects can then be used for a detailed description of the semantics of two kinds of nominalisations.

\section{Applications}

In the following section we will discuss some applications of the developed formal system. We will first show how to interpret the syntax trees from section 3 in a strictly compositional way.

\subsection{Compositionality}

We will develop a detailed interpretation for only one syntactic analysis. The necessary modification for the other trees are obvious. Let us consider Abney's analysis of Poss-ing gerunds.

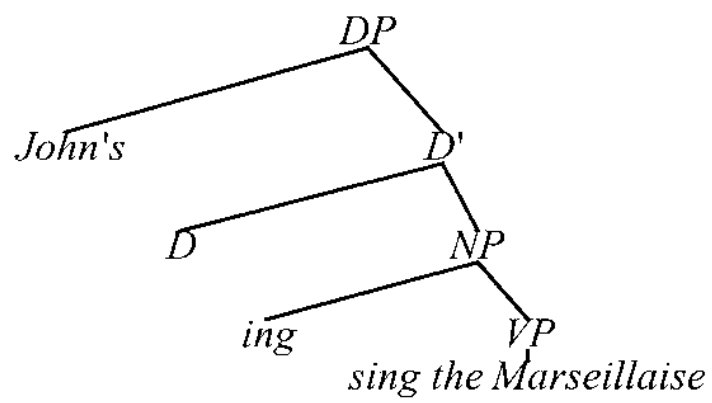

Poss-ing

Assume that the verb $\operatorname{sing}$ is represented by $\operatorname{sing}(\mathrm{x}, \mathrm{y}, \mathrm{a})$, where a is again a temporal parameter. The VP sing the Marseillaise is formed in the usual way by applying the propositional function corresponding to sing to the object the Marseilaise. Let us write $\mathrm{m}$ for the NP the Marseillaise. The VP is therefore represented by $\operatorname{sing}(\mathrm{x}, \mathrm{m}, \mathrm{a})$. So far there is nothing new. The semantic function of the abstract morphological element -ing is reification. Syntactically, -ing transforms a V-projection into an $\mathrm{N}$-projection. The corresponding semantic operation is the transformation of the propositional function $\operatorname{sing}(\mathrm{x}, \mathrm{m}, \mathrm{a})$ into the fluent valued function $\operatorname{sing}[\mathrm{x}, \mathrm{m}$, â]. The last step consists in applying the fluent valued function to the object John (j), which results in the fluent object $\operatorname{sing}[\mathrm{j}, \mathrm{m}$, $\hat{\mathrm{a}}]$, which is the semantic representation of the Poss-ing gerund John's singing the Marseillaise. In accordance with the observations from section $2.1 \mathrm{John}$ 's is not analysed as a determiner in this construction but is treated in the same way as John in Acc-ing gerunds.

Acc-ing gerunds are interpreted similarly. The only difference is that the reification process applies to $\operatorname{sing}(\mathrm{j}, \mathrm{m}, \mathrm{a})$, which is in accordance with Abney's analysis. The result is again the fluent object $\operatorname{sing}[\mathrm{j}, \mathrm{m}, \hat{\mathrm{a}}]$.

The compositional interpretation of Ing-of gerunds preceeds in the same way with one additional complexity, however. This complexity concerns the role of determiners, which can occur with perfect nominals but not with imperfect nominals. Note that John's is considered a determiner when this expression occurs as part of perfect nominals but not when it occurs as part of imperfect nominals. 


\subsection{Verbal Contexts and Determiners}

Before we analyse determiners we have to fix the denotations of the verbal contexts or containers in Vendler's terminology. If we stipulate the denotation of a loose container like surprised us to be a set of fluents, then according to the analysis so far, we predict that the sentence

John's singing the Marseillaise surprised us.

is semantically well-formed since the imperfect nominal John's singing the Marseillaise denotes a fluent object which may well be an element of the set surprised us. We have two possibilities for choosing denotations for narrow containers: sets of event-types or sets of event-tokens. In both cases we predict that the sentence

John's singing the Marseillaise took place at noon.

is semantically not well formed since a fluent can neither be an element of a set of event-types nor an element of a set of event-tokens. But on closer inspection, the second option seems to be more appropriate because narrow containers can be temporally modified. Since the time parameter of event-types is bound by an existential quantifier, there is no way to temporally modify event-types. By contrast, event-tokens, being pairs of event-types and times, can be readily modified by temporal operators. Therefore, if we choose (sets of) event-types as denotations for perfect nominals and (sets of) event-tokens as denotations of narrow containers, their behaviour with respect to temporal modification is explained. Specifically, we predict that temporal modification of perfect nominals is not possible, which is supported by the above-mentioned fact that the form having cooked of the dinner is not acceptable. A further advantage of choosing different denotation types for perfect nominals and narrow containers is that we may assume that it is possible to negate narrow containers without assuming that negation of perfect nominals is possible too. We can therefore assume that the negation of narrow containers is complementation with respect to the set of event-tokens, i.e. with respect to the set Happens. This explains the following two observations:

The singing of the song didn't occur at noon.

*John's kicking the cat didn't occur at noon.

The second fact follows since didn't occur at noon denotes a set of event-tokens - the complement of occur at noon with respect to Happens - which may not contain the fluent John's kicking the cat. In order to explain the first, we have to analyse the role of determiners. Since perfect nominals denote sets of event-types and narrow containers denote set of eventtokens, the task of determiners is to relate the two sets. This relationship can be established with the help of the Happens-predicate of the event-calculus. Under these assumptions, a sentence like Every singing of the aria took place at noon will be formalised as follows (here a abbreviates the NP the aria):

$$
\forall \mathrm{x}, \mathrm{s}(\operatorname{Happens}(\exists \mathrm{t} \cdot \operatorname{sing}[\mathrm{x}, \mathrm{a}, \mathrm{t}], \mathrm{s}) \rightarrow \text { took place at noon }(\exists \mathrm{t} \cdot \operatorname{sing}[\mathrm{x}, \mathrm{a}, \mathrm{t}], \mathrm{s}))
$$

On this analysis, the licensing conditions for determiners is the positive occurrence of the Happens-predicate in the restrictor. This immediately explains why imperfect nominals cannot occur with determiners, because fluents like break[x, r, â] are not allowed as arguments of the Happens-predicate. Therefore, an expression like 
is not acceptable.

In order to give a strictly compositional analysis of Abney's analysis of Ing-of gerunds we have to develop a semantic representation for the meanings of determiners. We will use lambda notation to unambigously denote functions. The general scheme for determiners that occur with perfect nominals is then:

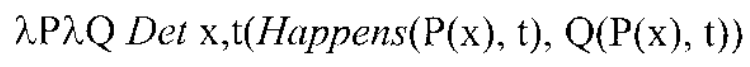

This scheme is best explained by working out a concrete example. Suppose then that $\lambda \mathrm{x} \exists \mathrm{t}$.sing $[\mathrm{x}, \mathrm{a}, \mathrm{t}]$ represents the perfect nominal singing of the aria. The determiner Every $=$ $\lambda \mathrm{P} \lambda \mathrm{Q}$ Every $\mathrm{x}, \mathrm{t}($ Happens $(\mathrm{P}(\mathrm{x}), \mathrm{t}), \mathrm{Q}(\mathrm{P}(\mathrm{x}), \mathrm{t}))$ applied to this nominal gives:

$\lambda \mathrm{Q}$ Every $\mathrm{x}, \mathrm{t}($ Happens $(\lambda \mathrm{x} \exists \mathrm{t} \cdot \operatorname{sing}[\mathrm{x}, \mathrm{a}, \mathrm{t}](\mathrm{x}), \mathrm{t}), \mathrm{Q}(\lambda \mathrm{x} \exists \mathrm{t} \cdot \operatorname{sing}[\mathrm{x}, \mathrm{a}, \mathrm{t}](\mathrm{x}), \mathrm{t})$, which reduces to $\lambda \mathrm{Q}$ Every $\mathrm{x}, \mathrm{t}($ Happens $(\exists \mathrm{t} \cdot \operatorname{sing}[\mathrm{x}, \mathrm{a}, \mathrm{t}], \mathrm{t}), \mathrm{Q}(\exists \mathrm{t} \cdot \operatorname{sing}[\mathrm{x}, \mathrm{a}, \mathrm{t}], \mathrm{t})$. This function, when applied to the narrow container took place at noon, results in Every $\mathrm{x}, \mathrm{t}($ Happens $(\exists \mathrm{t} . \operatorname{sing}[\mathrm{x}, \mathrm{a}, \mathrm{t}], \mathrm{t})$, took place at noon $(\exists \mathrm{t} \cdot \operatorname{sing}[\mathrm{x}, \mathrm{a}, \mathrm{t}], \mathrm{t})$, which is the generalised quantifier representation of the above formula. Therefore, Abney's syntactic analysis of Ing-of gerunds can be interpreted in a strictly compositional way too ${ }^{10}$.

To summarise we have arrived at the following denotation types for perfect versus imperfect nominals and narrow versus loose containers:

- perfect nominals

sets of event-types

- imperfect nominals

fluents

- narrow containers

sets of event-tokens

- loose containers

sets of pairs consisting of fluents and times

But what about a sentence like John's breaking of the records surprised us, where a perfect nominal occurs as an argument of a loose container?

\subsection{Coercion and Intensionality}

Vendler observed that perfect nominals tend to be interpreted like imperfect ones when they occur as arguments of loose containers. Thus, a paraphrase of the sentence The collapse of the Germans is unlikely is That the Germans collapsed is unlikely. No such paraphrase exists for The collapse of the Germans was gradual for the narrow container was gradual.

An informal description of the meaning of the sentence The collapse of the Germans is unlikely might run as follows: What is unlikely is the fact that an event characterised by the noun collapse of the Germans is happening. This intuition can be cast into a precise definition.

Definition 3 Let e be an event-type; then there exists a canonical fluent $\mathrm{f}$ associated to e defined by $\mathrm{f}:=$ Happens $[\mathrm{e}, \hat{\mathrm{a}}]$.

Let us demonstrate this definition with an analysis of the sentence The beheading of the king surprised $u s$. The formula representing this sentence is:

The $\mathrm{x}, \mathrm{s}($ Happens $(\exists \mathrm{a}$.behead $[\mathrm{x}$, the king, $\mathrm{a}], \mathrm{s})$, surprised us(Happens $[\exists \mathrm{a}$.behead $[\mathrm{x}$, the king, a], $\mathrm{a}], \mathrm{s}))$

\footnotetext{
${ }^{10}$ We refer the reader to Hamm/Zimmermann (2002) and Westerståhl (1989) for a detailed analysis of other determiners like the, John's etc. and for the analysis of quantifiers in object positions.
} 
An intuitive paraphrase of the formula is: Given that a unique event characterised by the phrase beheading of the king happened this very fact surprised us. Determiners here function similarily to determiners which relate nominals to narrow containers; however, in the case of coerced readings determiners relate event-types not to event-tokens but to the canonical fluents associated with them.

The type of coercion just encountered is of importance for the difference between intensional and extensional contexts too. As already observed, narrow containers are typical extensional contexts while loose containers are in general intensional contexts. Thus, if the king and the famous commander are one and the same person, then

The beheading of the king occurred at noon.

implies The beheading of the famous commander occurred at noon and vice versa. No such mutual dependence is observed in the case of The beheading of the king surprised us and The beheading of the famous commander surprised us.

Since the nominal beheading of the king is represented by $\exists$ a.behead $[\mathrm{x}$, the king, a $]$ and beheading of the famous commander by $\exists \mathrm{a}$. behead $[\mathrm{x}$, famous commander, a] they are different according to the intensional set up of the Feferman calculus. Therefore The beheading of the king surprised us may be true without The beheading of famous commander surprised us being true as well and vice versa. But now we have to face a problem. The same holds for the pair The beheading of the king occurred at noon and The beheading of the famous commander occurred at noon. However, as observed these sentences imply one another.

To solve this problem note that it seems reasonable to assume that event-types which are derived from equivalent formulas happen at the same time. They are extensional in this sense. The effect is captured formally by the following axiom:

Axiom $7 \quad$ Let $\phi$ and $\psi$ be logically equivalent formulas, then Happens $(\exists a . \phi(\mathbf{x}, \mathrm{a}), \mathrm{t}) \leftrightarrow \operatorname{Happens}(\exists \mathrm{a} \cdot \psi(\mathbf{x}, \mathrm{a}), \mathrm{t})$.

This is not yet sufficient to guarantee extensional equivalence of the pair The beheading of the king occurred at noon and The beheading of the famous commander occurred at noon. The equivalence is arrived at by the following empirical hypothesis:

Every narrow container is a Boolean combination of the Happens-predicate.

Since the sentence The beheading of the king occurred at noon is formalised as

The $\mathrm{x}, \mathrm{s}($ Happens $(\exists \mathrm{a}$. behead $[\mathrm{x}$, the king, a $], \mathrm{s})$, occurred at noon $(\exists \mathrm{a}$.behead $[\mathrm{x}$, the king, $\mathrm{a}], \mathrm{s}))$

Axiom 7 and the empirical hypothesis plus the assumption that the king and the famous commander are the same person force the two sentences to have the same truth value.

Examples for the use of fluents associated with event-types more involved than the intensional phrases above are provided by Cresswell's sentences.

\subsection{Negation of Event-Types}

Consider again the examples in (25).

(25) (a) The non-arrival of the train caused consternation.

(b) *the non-arrival of the train unexpectedly

(c) the unexpected non-arrival of the train 
(d) *The non-arrival of the train occurred at noon.

(e) Every non-arrival of a train causes consternation.

The problem the phrase non-arrival of the (a) train poses is that it exhibits the internal behaviour of a perfect nominal but the external behaviour of an imperfect nominal. Let us first consider the nominal arrival of the (a) train. Although this is a derived nominal, we take it as an event denoting expression". Its translation is therefore $\exists$ a.arrive $[\mathrm{x}, \mathrm{t}, \mathrm{a}]$, where $\mathrm{t}$ is short for the (a) train. The problem now is to analyse the effect of non. The obvious representation of non-arrival of the train as $\exists \mathrm{a}$. $\neg$ arrive $[\mathrm{x}, \mathrm{t}, \mathrm{a}] \mathrm{seems}$ to be out since this would turn nonarrival of the train into an event-type, which would not help to explain the external behaviour of this expression, which is that of an imperfect nominal as shown by (25)(d). For a way out, consider the Happens-predicate again. Given Happens(e,a), we can form the negation $\neg$ Happens(e,a) and then construct from this formula the fluent denoting term $\neg$ Happens $[\mathrm{e}, \hat{a}]$; intuitively this term denotes the fact that e didn't happen. Let us fix this observation as a definition.

Definition 4 The fluent negation $\approx$ e of an event-type e is defined by $\approx \mathrm{e}:=\neg$ Happens $[\mathrm{e}, \mathrm{a}]$.

With the help of definition 4 , a possible logical representation of the crucial sentence pair The non-arrival of the train surprised us versus *The non-arrival of the train occurred at noon is now:

$$
\begin{aligned}
& \text { The } \mathrm{x}, \mathrm{s}(\neg \text { Happens }(\exists \mathrm{a} \text { arrive }[\mathrm{x}, \mathrm{t}, \mathrm{a}], \mathrm{s}) \text {, surprised us }(\approx \exists \mathrm{a} \text { arrive }[\mathrm{x}, \mathrm{t}, \mathrm{a}], \mathrm{s}) \leftrightarrow \\
& \text { The } \mathrm{x}, \mathrm{s}(\neg \text { Happens }(\exists \text { a.arrive }[\mathrm{x}, \mathrm{t}, \mathrm{a}], \mathrm{s}), \text { surprised } \mathrm{s}(\neg \text { Happens }[\exists \mathrm{a} \text { arrive }[\mathrm{x}, \mathrm{t}, \mathrm{a}], \mathrm{o}], \mathrm{s}) \\
& \text { The } \mathrm{x}, \mathrm{s}(\neg \text { Happens }(\exists \mathrm{a} \text { arrive }[\mathrm{x}, \mathrm{t}, \mathrm{a}], \mathrm{s}), \text { occurred at noon }(\approx \exists \mathrm{a} \text { arrive }[\mathrm{x}, \mathrm{t}, \mathrm{a}], \mathrm{s}) \leftrightarrow \\
& \text { The } \mathrm{x}, \mathrm{s}(\neg \text { Happens }(\exists \text { a.arrive }[\mathrm{x}, \mathrm{t}, \mathrm{a}], \mathrm{s}), \text { occurred at noon }(\neg \text { Happens }[\exists \text { a.arrive }[\mathrm{x}, \mathrm{t}, \mathrm{a}], \hat{\mathrm{o}}], \mathrm{s})
\end{aligned}
$$

These formulas give a partial explanation for Cresswell's observations. First, the sentence The non-arrival of the train occurred at noon is out because occurred as noon is a set of eventtokens, and the pair ( $\neg$ Happens $[\exists \mathrm{a}$ arrive $[\mathrm{x}, \mathrm{t}, \mathrm{a}], \hat{\mathrm{o}}], \mathrm{s})$ cannot be an element of a set of event-tokens since $\neg$ Happens $[\exists$ a.arrive $[\mathrm{x}, \mathrm{t}, \mathrm{a}]$, ô] is not an event-type but a fluent (recall that event-tokens are pairs of event-types and times). On the other hand, ( $\neg$ Happens [ $\exists$ a.arrive $[\mathrm{x}$, $\mathrm{t}, \mathrm{a}], \hat{o}], \mathrm{s})$ may well be an element of surprised us since loose containers contain pairs of fluents and times. But there is still one problem left.

The condition ( $\neg$ Happens $(\exists$ a.arrive $[\mathrm{x}, \mathrm{t}, \mathrm{a}], \mathrm{s})$ in the restrictor of determiners is not the licensing condition we need for determiners. Determiners were licensed by a positive occurrence of the Happens-predicate in the restrictor. But suppose we introduce a negation which maps event-types to event-types and which satisfies the following postulate:

$$
\forall \mathrm{e}(\operatorname{Happens}(\sim \mathrm{e}, \mathrm{t}) \rightarrow \neg \text { Happens }(\mathrm{e}, \mathrm{t}))
$$

Postulate (28) turns $\sim$ into an antonymic negation. Such a negation seems to be required independently because of the Russian nominalisations negated by ne, for instance nesobljudenie (not-respecting). With (28) we can now choose the following translations for the sentences The non-arrival of the train surprised $u s$ and The non-arrival of the train occurred at noon.

\footnotetext{
11 This is in accordance with Vendler's observations that some derived nominals (like blizzard) are perfect nominals.
} 
The $\mathrm{x}, \mathrm{s}($ Happens $(\sim \exists$ a.arrive $[\mathrm{x}, \mathrm{t}, \mathrm{a}], \mathrm{s})$, surprised us $(\neg$ Happens $[\exists \mathrm{a}$.arrive $[\mathrm{x}, \mathrm{t}, \mathrm{a}], 0 \mathrm{o}], \mathrm{s})$

The $\mathrm{x}, \mathrm{s}($ Happens $(\sim \exists \mathrm{a}$.arrive $[\mathrm{x}, \mathrm{t}, \mathrm{a}], \mathrm{s})$, occurred at noon $(\neg$ Happens $[\exists \mathrm{a}$.arrive $[\mathrm{x}, \mathrm{t}, \mathrm{a}], \hat{\mathrm{o}}], \mathrm{s})$

These formulas satisfy the licensing conditions for the occurrence of determiners, and (26) and (27) can be derived from clause (28). These formalisations explain the puzzling character of Cresswell's examples too because according to the above formulas two different kind of negations interact in a non-trivial way.

However, we have to face a further problem now. As already observed, negation in perfect nominals - if it can occur at all - is not classical logical negation. The question then is why the strengthening of (28) with (29), which introduces classical negation of event-types, is not allowed?

$$
\forall \mathrm{e}(\neg \operatorname{Happens}(\mathrm{e}, \mathrm{t}) \rightarrow \operatorname{Happens}(\sim \mathrm{e}, \mathrm{t}))
$$

Before we go on investigating this particular problem, let us first see that it makes sense to introduce at least some Boolean connectives on the set of event-types. First, we observe that we can form conjunctions and disjunctions of perfect nominals. The following examples are acceptable and perfect nominals:

(30) (a) John's breaking of the record and his winning of the race

(b) John's breaking of the record or his winning of the race

For the analysis of these examples disjunctions and conjunctions of event-tpes seem to be required. It is easy to introduce such operations. First observe that if two formulas $\phi, \psi$ are given, we can form new event-types from event-types $\exists$ a. $\phi[\mathbf{x}, \mathbf{a}]$ and $\exists$ a. $\psi[\mathbf{x}, \mathbf{a}]$ by setting $\exists$ a. $\phi[\mathbf{x}, \mathbf{a}] \wedge \exists \mathbf{a} . \psi[\mathbf{x}, \mathbf{a}]:=\exists \mathrm{a} .(\phi \wedge \psi)[\mathbf{x}, \mathbf{a}]$ and similarily for $\exists$ a. $\phi[\mathbf{x}, \mathbf{a}] \vee \exists \mathbf{a} . \psi[\mathbf{x}, \mathbf{a}]$. However, since Happens is not a truth predicate ${ }^{12}$, we do not know how these new terms behave with respect to this predicate of the event-calculus. But we can stipulate proper behaviour by means of two axioms.
Axiom 8
Happens $\left(\mathrm{e} \wedge \mathrm{e}^{\prime}, \mathrm{t}\right) \leftrightarrow \operatorname{Happens}(\mathrm{e}, \mathrm{t}) \wedge \operatorname{Happens}\left(\mathrm{e}^{\prime}, \mathrm{t}\right)$
Axiom 9
Happens $\left(\mathrm{e} \vee \mathrm{e}^{\prime}, \mathrm{t}\right) \leftrightarrow$ Happens $(\mathrm{e}, \mathrm{t}) \vee \operatorname{Happens}\left(\mathrm{e}^{\prime}, \mathrm{t}\right)$

The question now is whether there are any reasons to reject (29)? To answer this question, we have to give a brief informal sketch of the approach to computing denotations in van Lambalgen/Hamm 2001.

In this paper, the computation of the denotation of expressions is viewed as a nonmonotonic process which on the basis of the description of a concrete situation incorporating lexical information (an episode in the terminology of van Lambalgen/Hamm 2001) delivers a minimal model of the situation. The computation process is given by a constraint logic program based on the axioms of the event calculus $E C$. Let us explain this in more detail.

An inference relation $q$ is monotonic if it satisfies: $\Gamma q \varphi$; then $\Gamma \cup \Sigma q \varphi$, where $\varphi$ is a formula and $\Gamma, \Sigma$ are sets of formulas. An inference relation is non-monotonic if it is not monotonic. So strengthening the antecedents preserves a given inference in monotonic systems, but it may destroy such an inference in non-monotonic systems.

Non-monotonic systems establish minimal models in the sense that nothing is assumed beyond what is given by the data. The algorithm which computes denotations always

\footnotetext{
${ }^{12}$ Note that this contrasts with the case of Holds At, which is a truth predicate.
} 
computes a minimal model compatible with the present data. This point bears some elaboration. Both monotonic and nonmonotonic reasoning start from the maxim:

assume only what is given in the premises

but they implement $(\mathrm{M})$ in different ways. Non-monotonic reasoning takes $(\mathrm{M})$ to mean: all existence assumptions beyond those required by the premises are false; by contrast, monotonic reasoning interprets $(\mathrm{M})$ as: suspend judgement on statements which do not follow (and whose negations do not follow) from the premises. In the interesting cases, these two interpretations of $(\mathrm{M})$ can be reformulated as follows. In non-monotonic reasoning, people construct a minimal model, i.e. a model which makes everything false except the given data, of the premise (which is often unique); in monotonic reasoning, they must consider all models of the premises. We believe that the intension or sense of an expression can be profitably identified with an algorithm constructing such minimal models. For a precise definition of Frege's notion sense using algorithms for the construction of denotations in minimal models, see van Lambalgen/Hamm (2001).

Let us now apply this general approach to the problem we encountered with (29). Instead of giving a general proof, we will demonstrate the refutation of (29) by way of a concrete example.

Assume that $n$ event-types are given and, further, that there is an episode which only mentions that event-type e happens at time t. What do we know about the minimal model $\mathbf{M}$ of this episode?

Certainly, Happens $(\mathrm{e}, \mathrm{t})$ is true in $\mathbf{M}$. Moreover, for all $\mathrm{e}_{\mathrm{i}} \neq \mathrm{e}, \rightarrow \operatorname{Happens}\left(\mathrm{e}_{\mathrm{i}}, \mathrm{t}\right)$ is true in $\mathbf{M}$ as well. Now suppose for some $\mathrm{e}_{\mathrm{j}} \neq \mathrm{e}$ and $\sim \mathrm{e}_{\mathrm{j}} \neq \mathrm{e}$. Then we have that $\neg \operatorname{Happens}\left(\mathrm{e}_{\mathrm{j}}, \mathrm{t}\right)$ and $\neg$ Happens $\left(\sim \mathrm{e}_{j}, \mathrm{t}\right)$ are true in $\mathbf{M}$ since $\mathbf{M}$ is a minimal model. From (29) we derive now: Happens $\left(\sim \mathrm{e}_{\mathrm{j}}, \mathrm{t}\right)$ and Happens $\left(\sim \sim \mathrm{e}_{\mathrm{j}}, \mathrm{t}\right)$. Therefore $\sim \mathrm{e}_{\mathrm{j}}=\mathrm{e}=\sim \sim \mathrm{e}_{\mathrm{j}}$. It follows from $(28)$ and Happens $\left(\sim \sim \mathrm{e}_{\mathrm{j}}, \mathrm{t}\right)$ that $\neg$ Happens $\left(\sim \mathrm{e}_{\mathrm{j}}, \mathrm{t}\right)$ which contradicts Happens $(\mathrm{e}, \mathrm{t})$.

This example demonstrates that (29) prevents the computation of denotations in minimal models. We therefore conclude that only antonymic negation, i.e. a negation satisfying (28), is compatible with event-types.

\section{References}

Abney, Steven (1987): The English Noun Phrase in its Sentential Aspect. PhD Thesis, Massachusetts Institute of Technology.

Chierchia, Gennaro (1988): Topics in the Syntax and Semantics of Infinitives and Gerunds. New York: Garland Publishing, Inc..

Chomsky, Noam (1981): Lectures on Government and Binding. Dordrecht: Foris.

Cresswell, Maxwell (1985): Adverbial Modification. Chapter V. Dordrecht: Reidel.

Feferman, Solomon (1984): Toward Useful Type-Free Theories I. The Journal of Symbolic Logic 49, 75-111.

Hamm, Fritz/van Lambalgen, Michiel (2000): Nominalization, the Progressive and Event Calculus. Amsterdam/Tübingen, to appear in: Linguistics and Philosophy.

Hamm, Fritz/Zimmermann, Thomas Ede (2002): Quantifiers and Anaphora. In: Hamm, Fritz/Zimmermann, Thomas Ede (eds.): Linguistische Berichte, Sonderheft: SEMANTIK.

Hindsill, Darrin (2001): On the Turning of Verbs into Nouns. MA-thesis, University of Amsterdam, MOL-200112 .

Jespersen, Otto (1933): Essentials of English Grammar. London: Allen \& Unwin.

Koptejevskaja-Tamm, Maria (1993): Nominalizations. London \& New York: Routledge.

van Lambalgen, Michiel/Hamm, Fritz (2001): Moschovakis' Notion of Meaning as Applied to Linguistics. Amsterdam/Tübingen, to appear in: Logic Colloquium 2001.

Parsons, Terence (1990): Events in the Semantics of English. Cambridge/Mass.: MIT Press.

Portner, Paul (1991): Situation Theory and the Semantics of Propositional Expressions. PhD Thesis, University of Massachusetts at Amherst.

Poutsma, H. (1923): The Infinitive, the Gerund and the Particles of the English Verb. Groningen: Nordhoff. 
Pullum, Geoffrey (1991): English Nominal Gerund Phrases as Noun Phrases witl Verb-Phrase Heads. Linguistics 29, 763-799.

Schachter, Paul (1976): A Nontransformational Account of Gerundive Nominals in English. Linguistic Inquiry 7, 1-55.

Shanahan, Murray (1997): Solving the Frame Problem - A Mathematical Investigation of the Common Sense Law of Inertia. Cambridge/Mass.: MIT Press.

Steedman, Mark (1997): Temporality. In: van Benthem, Johan/ter Meulen, Alice (eds.): Handbook of Logic and Language. Amsterdam: Elsevier.

Tovena, L.M. (2001): Negation as Failure. In: Hoeksema, Jack/Rullmann, Hotze/Sanchez-Valencia, Victor/van der Wouden, Ton (eds.): Perspectives on Negation and Polarity Items. Amsterdam: John Benjamins.

Vendler, Zeno (1967): Linguistics in Philosophy. Ithaca, New York: Cornell University Press.

Vendler, Zeno (1968): Adjectives and Nominalizations. The Hague: Mouton.

Westerstăhl, Dag (1989): Quantifiers in Formal and Natural Languages. In: Gabbay, D./Guenthner, F. (eds.): Handbook of Philosophical Logic, Vol. IV. Dordrecht: Reidel.

Zimmermann, Ilse (1988): Nominalisierungen mit dem Präfix ne im Russischen. Zeitschrift für Phonetik, Sprachwissenschaft und Kommunikationsforschung 41, 23-30.

Zucchi, Alessandro (1993): The Language of Propositions and Events. Dordrecht: Reidel. 